\title{
An optical FSK transmitter based on an integrated DFB laser-EA modulator and its application in optical labeling
}

Zhang, Jianfeng; Chi, Nan; Holm-Nielsen, Pablo Villanueva; Peucheret, Christophe; Jeppesen, Palle

Published in:

I E E E Photonics Technology Letters

Link to article, DOI:

10.1109/LPT.2003.813415

Publication date:

2003

Document Version

Publisher's PDF, also known as Version of record

Link back to DTU Orbit

Citation (APA):

Zhang, J., Chi, N., Holm-Nielsen, P. V., Peucheret, C., \& Jeppesen, P. (2003). An optical FSK transmitter based on an integrated DFB laser-EA modulator and its application in optical labeling. I E E E Photonics Technology Letters, 15(7), 984 - 986. https://doi.org/10.1109/LPT.2003.813415

\section{General rights}

Copyright and moral rights for the publications made accessible in the public portal are retained by the authors and/or other copyright owners and it is a condition of accessing publications that users recognise and abide by the legal requirements associated with these rights.

- Users may download and print one copy of any publication from the public portal for the purpose of private study or research.

- You may not further distribute the material or use it for any profit-making activity or commercial gain

- You may freely distribute the URL identifying the publication in the public portal 


\title{
An Optical FSK Transmitter Based on an Integrated DFB Laser-EA Modulator and Its Application in Optical Labeling
}

\author{
Jianfeng Zhang, Nan Chi, Pablo V. Holm-Nielsen, Christophe Peucheret, and Palle Jeppesen, Member, IEEE
}

\begin{abstract}
An optical frequency-shift-keying (FSK) transmitter based on an integrated distributed feedback laser-electroabsorption modulator is proposed and demonstrated. The feasibility of its application in optical labeling is also validated by the experimental results. The generated optical signal, consisting of a 10-Gb/s intensity-modulated payload and a 312-Mb/s FSK label, can be recovered error free after transmission over $88-\mathrm{km}$ standard single-mode fiber.
\end{abstract}

Index Terms-Distributed feedback (DFB) laser, electroabsorption (EA) modulator, optical frequency-shift keying (FSK), optical label switching.

\section{INTRODUCTION}

A LL-OPTICAL label switching implements the packet routing and forwarding functions of multiprotocol label switching directly in the optical layer, which is a promising technology for the next-generation wavelength-division-multiplexing networks. Several optical labeling methods have been proposed and demonstrated as possible solutions [1], in which the label is attached by time multiplexing or subcarrier multiplexing with the data payload. The optical label can also be realized by angle modulation that is orthogonal to the intensity-modulated (IM) payload [2], [3]. In a direct detection system, the label information can be modulated in either differential phase-shift-keying (DPSK) or frequency-shift-keying (FSK) format. The feasibility of the optical DPSK labeling has been experimentally validated [3], [4]. However, this scheme imposes stringent requirements on the laser linewidth. The scheme of combined FSK/IM modulation was demonstrated to be more applicable in practical networks [5], [6].

In the FSK labeling scheme, an ideal optical FSK transmitter impresses the label information upon the optical carrier's frequency through FSK modulation without affecting its intensity. Then the optically labeled packet can be formed when the payload information is modulated on the carrier's intensity.

The optical FSK modulation can be achieved simply by directly modulating the electrical current of a distributed feedback (DFB) or distributed Bragg reflector laser diode [7]. However, the drive current variation always results in a simulta-

Manuscript received January 9, 2003; revised March 18, 2003. This work was supported by the European Commission under the Switching Technologies for Optically Labeled Signals (STOLAS) project.

The authors are with Research Center Communications, Optics, and Materials, Technical University of Denmark, Lyngby, 2800 Denmark (e-mail: jz@com.dtu.dk).

Digital Object Identifier 10.1109/LPT.2003.813415

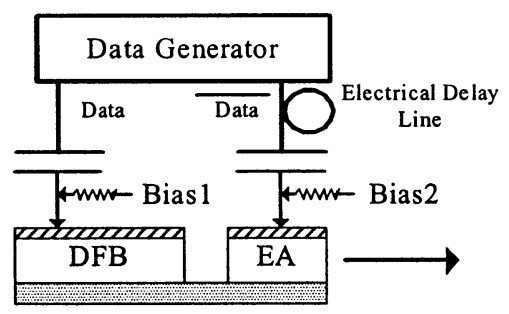

Fig. 1. Configuration of the proposed optical FSK transmitter

neous intensity modulation of the emitted light. Obviously, such a residual intensity modulation has a detrimental effect on the IM payload. To overcome this problem, we propose a novel optical FSK transmitter based on a commercially available integrated DFB laser-electroabsorption (EA) modulator. In Section II, the operation principle and performance of the proposed transmitter are described. In Section III, its application in optical FSK labeling is experimentally investigated in an $88-\mathrm{km}$ single-mode fiber (SMF) transmission link. In Section IV, summarizing conclusions are given.

\section{OPERATION PRINCIPLE AND PERFORMANCE}

The configuration of the proposed optical FSK transmitter is shown in Fig. 1. The DFB laser is driven with a bias current above threshold and a relatively small modulation current. The current modulation results in both intensity and frequency modulation of the output light. To remove the intensity variation of the laser's output, the inverse electrical data is injected into the integrated EA modulator with appropriate time delay and modulation voltage. In this way, a constant amplitude optical FSK signal is generated. In the methods reported in the literature [2], the input current variation has to be small to minimize the residual IM, which in turn results in a small FSK tone spacing that makes coherent detection necessary.

The measured optical characteristics of the DFB laser-EA modulator are shown in Fig. 2. As indicated in Fig. 2(a), the variation of the injection current will change both the output power and the wavelength. In the high current regime, a modulation current of nearly $30 \mathrm{~mA}$ is needed to achieve a $20-\mathrm{GHz}$ $(\sim 0.16 \mathrm{~nm})$ frequency deviation, which is accompanied by a 3-dB intensity variation. The integrated EA modulator shows a modulation efficiency of nearly $5 \mathrm{~dB} / \mathrm{V}$, as shown in Fig. 2(b).

Fig. 3 shows the measured eye diagrams and optical spectrum of the FSK signal when the DFB laser is driven with a 90-mA bias current and a 30-mA modulation current at $1 \mathrm{~Gb} / \mathrm{s}$. 


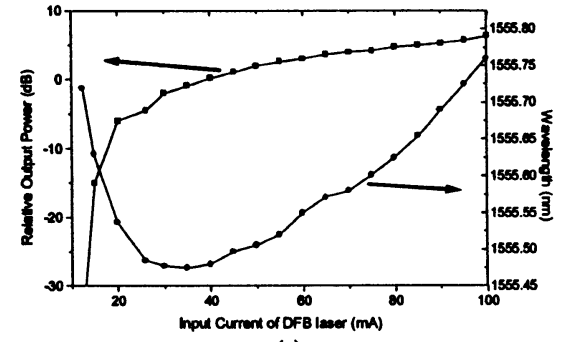

(a)

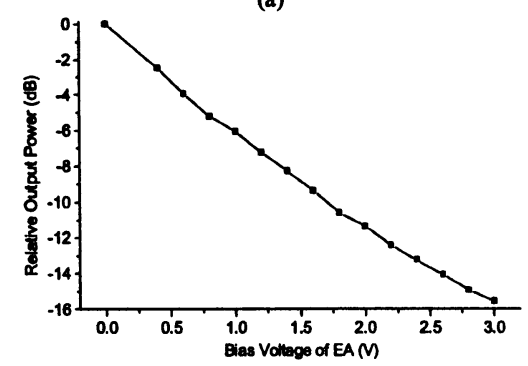

(b)

Fig. 2. Optical characteristics of the integrated DFB laser-EA modulator.

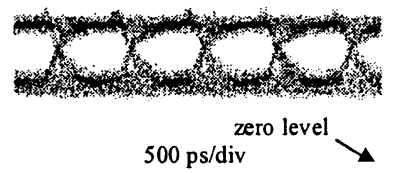

(a)

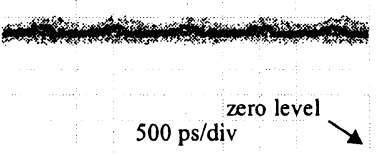

(b)

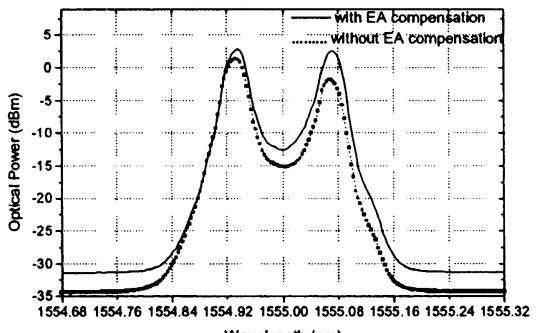

(c)

Fig. 3. (a) Eye diagram showing the residual intensity modulation after direct modulation of the DFB laser in order to obtain $20-\mathrm{GHz}$ tone spacing FSK modulation at $1 \mathrm{~Gb} / \mathrm{s}$. (b) Eye diagram after EA compensation. (c) Optical spectrum before/after EA compensation.

Without EA compensation, the current modulation of the DFB laser results in a nearly 3-dB intensity variation of the output light. As shown in its spectrum, the direct modulation generates two asymmetric optical tones, indicating that the generated FSK signal is accompanied by a residual intensity modulation. By driving the EA modulator with the inverse data signal, the residual intensity fluctuation is removed and a symmetrical FSK spectrum around $1555 \mathrm{~nm}$ can be obtained. Fig. 3(c) shows that the frequency deviation of the FSK signal is around $20 \mathrm{GHz}$.

To evaluate the FSK transmitter's performance, a fiber Bragg grating (FBG) is used as an optical frequency discriminator to achieve the frequency-to-intensity conversion, i.e., FSK demodulation. The optical eye diagram and the spectrum of the converted signal are shown in Fig. 4. By utilizing the sharp edge of the FBG, only one tone of the FSK is filtered out while the other one is suppressed to be $15 \mathrm{~dB}$ lower. From the eye diagram, the extinction ratio of the converted signal is measured to be $13 \mathrm{~dB}$.

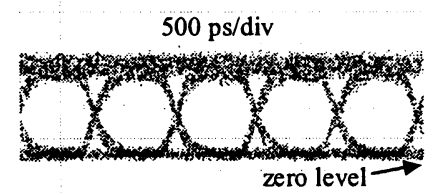

(a)

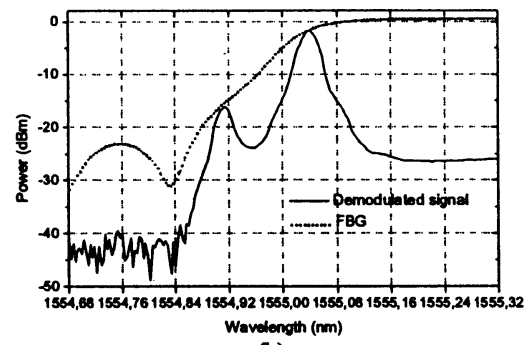

(b)

Fig. 4. (a) Eye diagram (b) optical spectrum of the demodulated FSK signal.

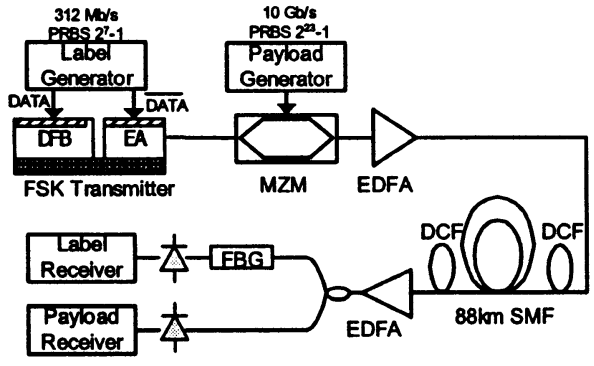

Fig. 5. Experimental setup.

The measurement also shows that both the DFB laser and the EA modulator have 3-dB modulation bandwidths of $2.5 \mathrm{GHz}$. Therefore, the operation bit-rate of this FSK transmitter can vary from $155 \mathrm{Mb} / \mathrm{s}$ to $2.5 \mathrm{~Gb} / \mathrm{s}$ without degraded performance.

\section{APPLICATION IN OPTICAL FSK LABELING}

In an FSK label switched network, an optical FSK transmitter is necessary in both edge nodes and core nodes [2], [6]. To investigate the performance of the optical FSK transmitter in edge node applications, an 88-km SMF transmission link was set up, as shown in Fig. 5. The optically labeled signal consisting of a $10-\mathrm{Gb} / \mathrm{s}$ payload and a $312-\mathrm{Mb} / \mathrm{s}$ label was first generated, then transmitted over 88-km SMF, and finally detected using direct detection receivers.

Two pseudorandom pattern generators were used to generate the payload and label information. The label information was impressed upon the optical carrier $(1555.0 \mathrm{~nm})$ through FSK modulation, while the payload information was added by a 10-Gb/s Mach-Zehnder intensity modulator. The power of the labeled signal was amplified to $10 \mathrm{dBm}$ and input into the fiber. The transmission span consisted of $88-\mathrm{km}$ SMF and a matching length of dispersion compensating fiber (DCF). The DCF was inserted into the link based on a hybrid dispersion compensation map (i.e., split equally before and after the transmission fiber) to give optimized transmission performance. At the receiver node, the labeled signal was split using a 3-dB optical coupler. One arm was directly detected by a photodiode and, thus, the optical payload was converted into the electrical 


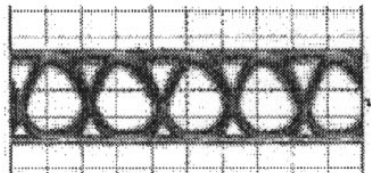

(a) $50 \mathrm{ps} / \mathrm{div}$

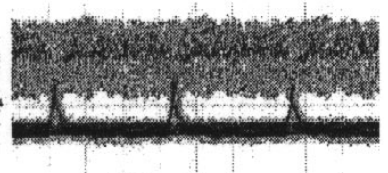

(b) $1 \mathrm{~ns} / \mathrm{diy}$
Fig. 6. Eye diagrams of (a) extracted payload and (b) extracted label.

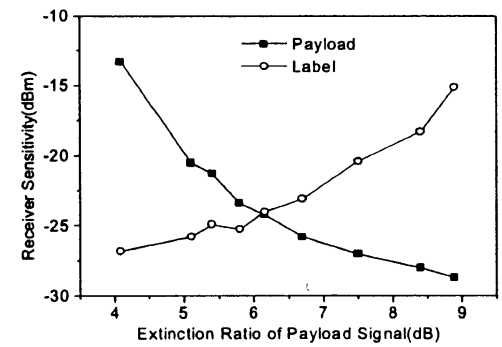

(a)

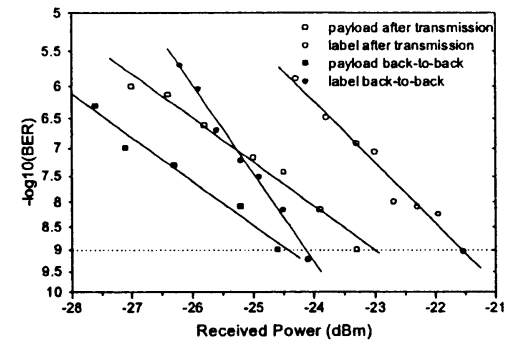

(b)

Fig. 7. (a) Payload and label receiver sensitivity versus extinction ratio of the payload. (b) BER performance of the optically labeled signal.

domain. In the other arm, an FBG was used to achieve the FSK demodulation. The demodulated label was then received by an electrical receiver with $1.8-\mathrm{GHz}$ bandwidth. Fig. 5 shows the eye diagrams of the extracted payload and label after transmission.

In the present labeling scheme, crosstalk is introduced between the payload and label; the received label eye diagram has a multilevel structure due to the intensity modulation of the payload, as indicated in Fig. 6(b). The degraded performance is also partly attributed to the nonoptimized receiver bandwidth. Fig. 7(a) shows the relation between the measured receiver sensitivities of the payload and label and the modulation depth of the payload in the back-to-back case. A good tradeoff between the label and payload performance can be achieved with nearly 6-dB extinction ratio. Fig. 7(b) shows the transmission performance of the signal with $6-\mathrm{dB}$ extinction ratio. The transmission penalties for label and payload are 2.2 and $1.2 \mathrm{~dB}$, respectively. The experimental results also show that the transmission link does not have error-free performance if no intensity compensation scheme is applied at the FSK transmitter.

\section{CONCLUSION}

We have proposed and demonstrated a novel optical FSK transmitter based on a commercially available integrated DFB laser-EA modulator, whose performance in the optical FSK labeling scheme was also experimentally investigated. By using such a transmitter, an optically labeled signal consisting of a $10-\mathrm{Gb} / \mathrm{s}$ payload and a $312-\mathrm{Mb} / \mathrm{s}$ label was generated. Both payload and label data could be recovered error free after transmission over 88-km SMF, validating the applicability of this FSK transmitter in optical labeling.

\section{REFERENCES}

[1] D. J. Blumenthal, B. E. Olsson, G. Rossi, T. E. Dimmick, L. Rau, M. Masanovic, O. Lavrova, R. Doshi, O. Jerphagnon, J. E. Bowers, V. Kaman, L. A. Coldren, and J. Barton, "All-optical label swapping networks and technologies," J. Lightwave Technol., vol. 18, pp. 2058-2075, Dec. 2000

[2] T. Koonen, J. Jennen, H. D. Warrdt, I. D. Monroy, I. D. Sulur, and G. Morthier, "Optical packet routing in IP-over-WDM networks deploying two-level optical labeling," in Proc. ECOC 2001, Paper THL2.1.

[3] M. Hickey and L. Kazovsky, "The STARNET coherent WDM computer communication network: experimental transceiver employing a novel modulation format," J. Lightwave Technol., vol. 6, pp. 876-884, May 1994.

[4] N. Chi, B. Carlsson, J. Zhang, P. V. Holm-Nielsen, C. Peucheret, and P. Jeppesen, "All-optical transparent wavelength conversion of an optically labeled signal in ASK/DPSK orthogonal modulation," in Proc. LEOS 2002, Paper MF3.

[5] M. Hickey and L. Kazovsky, "Combined frequency and amplitude modulation for the STARNET WDM computer communication network," IEEE Photon. Technol. Lett., vol. 6, pp. 1473-1475, Dec. 1994.

[6] E. N. Lallas, N. Skarmoutsos, and D. Syvridis, "An optical FSK-based label coding technique for the realization of the all-optical label swapping," IEEE Photon. Technol. Lett., vol. 14, pp. 1472-1474, Oct. 2002.

[7] R. S. Vodhanel, A. F. Elrefaie, M. Z. Iqbal, R. E. Wagner, J. L. Gimlett, and S. Tsuji, "Performance of directly modulated DFB lasers in 10-Gb/s ASK/FSK/DPSK lightwave systems," J. Lightwave Technol., vol. 8, pp. 1379-1385, Jan. 1990. 